\title{
Seleksi Calon Pegawai Honorer pada Dinas Penanaman Modal dan Pelayanan Terpadu Satu Pintu Kota Pematangsiantar Menggunakan Metode Profile Matching
}

\author{
Silvia Ayu1, Muhammad Zarlis' ${ }^{2}$, Suhada ${ }^{3}$ \\ STIKOM Tunas Bangsa Pematangsiantar \\ Jl. Jend. Sudirman Blok A No. 1-3 Pematangsiantar, 0622-7436800/062222431 \\ Email : silviaayu068@gmail.com
}

\begin{abstract}
Honorary employees are needed in each agency so that it requires a selection process. Assessment and decision making in selection are usually subjective, especially if there are several prospective honorary employess who have capabilities that are not much different. Decision support system help in the selection of candidates in a way that is fairer and easier to use. The calculation in this study is made in the form of selection of candidates for honorary employees with the Profile Matching method. This calculation was used to assist in the selection of competency assessors for prospective temporary employees at the Pematangsiantar City One Stop Investment and Integrated Services Office, with several considerations including written tests, interviews and personality assessments. This Profile Matching Method will compare between the profile of prospective honorary employees and the ideal profile of honorary employees. The smaller the gap or (gap) will make the opportunity to pass the selection even greater.
\end{abstract}

Keyword : profile matching, selection of honorary employees.

Abstrak-Pegawai honorer sangat dibutuhkan disetiap instansi sehingga memerlukan proses seleksi. Penilaian dan pengambilan keputusan dalam seleski biasanya bersifat subjektif terutama jika ada beberapa calon pegawai honorer yang memiliki kemampuan tidak jauh berbeda. Sistem pendukung keputusan membantu dalam pemilihan kandidat dengan cara lebih adil serta mudah digunakan. Perhitungan pada penelitian ini yang dibuat berupa Seleksi penerimaan calon pegawai honorer dengan metode Profile Matching. Perhitungan ini digunakan untuk membantu seleksi dalam melakukan penilai kompetensi calon pegawai honorer di Dinas Penanaman Modal dan Pelayanan Terpadu Satu Pintu Kota Pematangsiantar, dengan beberapa pertimbangan penilaian antara lain tes tertulis, wawancara dan penilaian kepribadian. Metode Profile Matching ini akan membandingkan antara profile calon pegawai honorer dengan profile ideal pegawai honorer. Selisi atau (gap) yang semakin kecil akan membuat kesempatan untuk lolos seleksi semakin besar.

Kata kunci : Sistem Pendukung Keputusan, Profile matching, Pegawai honorer

\section{PENDAHULUAN}

Perkembang teknologi yang semakin maju dan berkembang sangat pesat saat ini dapat membantu bagian kepegawaian yang bertugas untuk mengatur dan menentukan kegiatan penerimahan pegawai hororer (Non PNS) yang biasanya dibutuhkan untuk meringankan perkerjaan Pegawai Nergi Sipil, dimana setiap instansi pemerintahan pasti membutuhkan pegawai hororer. 
Dalam menyeleksi calon pegawai hororer penulis memiliki beberapa kriteria tertentu diantarnya Tes Tertulis, Wawacara dan Penilaian Kepribadian. Pada penelitian ini penulis akan mengangkat suatu kasus yang mencari alternative terbaik untuk mendapat orang-orang yang berkualitas yang dapat berkerja di instansi tersebut. Dengan berdasarkan kriteria yang sudah ditentukan dengan metode Profile matching. Untuk penyeleksian calon pegawai dengan jabatan honor "Dikutip dari penelitian terdahulu, metode Profil Matching dapat di implementasi dalam sebuah sistem pendukung keputusan untuk melakukan penilaian kelayakan / kelulusan proposal usulan penelitian. Penggunaan sistem pendukung keputusan dengan menerapkan metode Profil Matching dapat meningkatkan akurasi penilaian proposal secara profesional dan proporsional berdasarkan kriteria penilaian yang telah ditentukan"[1].

\section{METODOLOGI PENELITIAN}

Pada penelitian ini disajikan beberapa kajian tentang metode penelitian sebagai berikut :

\subsection{Metode Pengumpulan Data}

Pengumpulan data merupakan proses pengadaan data primer, untuk kebutuhan suatu penelitian. Adapun teknik pengumpulan data dalam penelitian ini yaitu :

a. Penelitian Kepustakaan (Library Research) yaitu memanfaatkan perpustakaan sebagai sarana dalam mengumpulkan data, dengan mempelajari buku - buku sebagai bahan referensi. Hal ini dilakukan dengan membaca tulisan berupa buku dan jurnal yang berkaitan dengan kasus yang penulis angkat.

b. Penelitian Lapangan (Field Work Research) yaitu penelitian yang dilakukan secara langsung dilapangan dengan menggunakan beberapa teknik sebagai berikut:

1. Observasi adalah metode pengumpulan data dengan cara mengadakan pengamatan langsung terhadap berbagai kegiatan yang ada. Hal ini penulis lakukan dengan melakukan pengamatan langsung di lokasi penelitian guna mencari data-data yang diperlukan dalam penelitian ini seperti pengambilan sample alternatif dan kriteria penilaian yang akan diuji.

2. Wawancara adalah proses pengumpulan data atau informasi melalui tatap muka antara pihak penanya (interviewer) dengan pihak yang ditanya atau penjawab (interviewee). Hal ini penulis lakukan dengan bertanya langsung kepada pihak-pihak terkait serta yang bertanggung jawab dalam pemilihan dinas penanaman modal dan pelayanan terpadu satu pintu. Hal ini penulis lakukan dengan membuat dokumen penilaian sample alternatif terhadap kriteria yang sebelumnya telah didiskusikan saat sesi wawancara.

\subsection{Metode Profile Matching}

"Metode pencocokan profil (Profile Matching) adalah sebuah mekanisme pengambilan keputusan dengan mengasumsikan bahwa terdapat tingkat variable predictor yang ideal yang harus dimiliki oleh pelamar, bukannya tingkat minimal yang harus dipenuhi atau dilewati. Dalam pencocokan profil, dilakukan identifikasi terhadap kelompok karyawan yang baik maupun buruk" [2]. 


\section{HASIL DAN PEMBAHASAN}

\subsection{Analisis Data}

Dari hasil pengumpulan data diatas, penulis menggunakan data Teknik sampling adalah teknik yang dilakukan untuk menentukan sampel. Jadi, sebuah penelitian yang baik haruslah memperhatikan dan menggunakan sebuah teknik dalam menetapkan sampel yang akan diambil sebagai subjek penelitian.

Tabel 1. Sampel Data Penelitian

\begin{tabular}{|l|l|l|l|l|}
\hline No & Nama & Tempat Lahir & Agama & Pendidikan \\
\hline 1 & Sugeng Adi Prasetyo, S.T & Medan & Islam & S1 \\
\hline 2 & Rika Andriani. & Pamatang Siantar & Islam & SMK \\
\hline 3 & Rangga Muhammad Nugraha & Pamatang Siantar & Islam & SMK \\
\hline 4 & Eriyawati Supardjo, A.Md & Pamatang Siantar & Islam & DIII \\
\hline 5 & Suryani & Pamatang Siantar & Islam & SMK \\
\hline
\end{tabular}

\begin{tabular}{|l|l|l|l|l|l|}
\hline No & Nama & Keahlian & \multicolumn{2}{|l|}{ Hasil Tes Wawara } & Usia \\
\cline { 3 - 6 } & & Kecakapan & Kredibilitas & \\
\hline 1 & $\begin{array}{l}\text { Sugeng Adi } \\
\text { Prasetyo, S.T }\end{array}$ & $\begin{array}{l}\text { Ahli dibidang } \\
\text { Teknik Mesin } \\
\text { Komputer }\end{array}$ & 89 & 95 & $\begin{array}{l}22 \\
\text { Tahun }\end{array}$ \\
\hline 2 & Rika Andriani. & $\begin{array}{l}\text { Ahli Dibidang } \\
\text { Sistem Informasi }\end{array}$ & 98 & 87 & $\begin{array}{l}23 \\
\text { Tahun }\end{array}$ \\
\hline 3 & $\begin{array}{l}\text { Rangga } \\
\text { Muhammad } \\
\text { Nugraha }\end{array}$ & $\begin{array}{l}\text { Ahli dibidang } \\
\text { pemasaran }\end{array}$ & 75 & 85 & $\begin{array}{l}19 \\
\text { Tahun }\end{array}$ \\
\hline 4 & $\begin{array}{l}\text { Eriyawati } \\
\text { Supardjo, A.Md }\end{array}$ & Ahli Programmer & 90 & 81 & $\begin{array}{l}20 \\
\text { Tahun }\end{array}$ \\
\hline 5 & $\begin{array}{l}\text { Suryani } \\
\text { Ahli dibidang } \\
\text { perkantoran }\end{array}$ & 90 & 88 & $\begin{array}{l}18 \\
\text { Tahun }\end{array}$ \\
\hline
\end{tabular}

Data yang digunakan berupa data kriteria dengan pembobotan sesuai dengan rating kepentingannya. Data kriteria yang digunakan dalam penentuan koordinator Penelitian ini merupakan penelitian kualitatif dengan rancangan studi kasus, Pendekatan kualitatif digunakan dalam penelitian ini untuk mendeskripsikan bagaimana penggunaan Profile Matching di perguruan tinggi. Perhitungan dalam Metode Profile Matching akan dijelaskan mulai dari proses perhitungan bobot setiap aspek kriteria sampai perhitungan nilai akhir yang digunakan untuk penganbilan keputusan. Berikut data alternatif yang digunakan dalam penentuan pemilihan pegawai honorer dapat dilihat pada tabel berikut.

Tabel 2. Data Alternatif

\begin{tabular}{|l|l|l|l|}
\hline No & \multicolumn{2}{|l|}{ Kriteria } & Nilai Profil \\
\hline 1 & A1 & Sugeng Adi Prasetyo, S.T & 4 \\
\hline 2 & A2 & Rika Andriani. & 4 \\
\hline 3 & A3 & Rangga Muhammad Nugraha & 3 \\
\hline 4 & A4 & Eriyawati Supardjo, A.Md & 2 \\
\hline 5 & A5 & Suryani & 2 \\
\hline
\end{tabular}


Data yang digunakan berupa data kriteria dengan pembobotan sesuai dengan rating kepentingannya. Data kriteria yang digunakan dalam pemilihan pegawai honorer pada tabel berikut.

Tabel 3. Data Kriteria

\begin{tabular}{|l|l|l|l|l|}
\hline No & \multicolumn{2}{|l|}{ Kriteria } & \multicolumn{2}{l|}{ Bobot } \\
\hline 1 & $\mathrm{C}_{1}$ & Pendidikan & $40 \%$ & 4 \\
\hline 2 & $\mathrm{C}_{2}$ & Keahlian & $15 \%$ & 4 \\
\hline 3 & $\mathrm{C}_{3}$ & Kecakapan & $15 \%$ & 2 \\
\hline 4 & $\mathrm{C}_{4}$ & Kredibilitas & $20 \%$ & 3 \\
\hline 5 & $\mathrm{C}_{5}$ & Usia & $10 \%$ & 2 \\
\hline
\end{tabular}

Dengan tingkat kepentingan sebagai berikut :

Tabel 4. Tingkat Bobot Nilai

\begin{tabular}{|l|l|l|l|}
\hline No & Nilai & Bobot & Keterangan \\
\hline 1 & $90-100$ & 5 & Sangat Baik \\
\hline 2 & $80-89$ & 4 & Baik \\
\hline 3 & $65-79$ & 3 & Cukup Baik \\
\hline 4 & $45-64$ & 2 & Kurang Baik \\
\hline 5 & $<45$ & 1 & Tidak Baik \\
\hline
\end{tabular}

\subsection{Perhitungan Manual}

Tahapan-tahapan proses dalam perhitungan manual Profile Matching meliputi proses pemetaan gap, penentuan bobot nilai gap, perhitungan dan pengelompokan core dan secondary factor, perhitungan nilai total, perhitungan hasil akhir dan proses perankingan.

1. Menentukan aspek dan sub aspek yang akan diukur dan dinilai.

Hal-hal yang diukur dari aspek ini adalah Tes terulis, Wawancara dan Penilaian Kepribadian.

Tabel 5. Data Kriteria

\begin{tabular}{|c|c|c|c|c|c|c|}
\hline \multirow[t]{2}{*}{ No } & \multirow[t]{2}{*}{ Nama } & \multirow[t]{2}{*}{ Keahlian } & \multicolumn{2}{|c|}{ Hasil Tes Wawancara } & \multirow[t]{2}{*}{ Usia } & \multirow[t]{2}{*}{ Pendidikan } \\
\hline & & & Kecakapan & Kredibilitas & & \\
\hline 1 & $\begin{array}{l}\text { Sugeng Adi } \\
\text { Prasetyo, S.T }\end{array}$ & $\begin{array}{l}\text { Ahli dibidang } \\
\text { Teknik Mesin } \\
\text { Komputer }\end{array}$ & 85 & Baik & $\begin{array}{l}22 \\
\text { Tahun }\end{array}$ & S1 \\
\hline 2 & $\begin{array}{l}\text { Rika } \\
\text { Andriani. }\end{array}$ & $\begin{array}{l}\text { Ahli Dibidang } \\
\text { Sistem } \\
\text { Informasi }\end{array}$ & 90 & Sangat Baik & $\begin{array}{l}23 \\
\text { Tahun }\end{array}$ & SMK \\
\hline 3 & $\begin{array}{l}\text { Rangga } \\
\text { Muhammad } \\
\text { Nugraha }\end{array}$ & $\begin{array}{l}\text { Ahli dibidang } \\
\text { pemasaran }\end{array}$ & 75 & Cukup Baik & $\begin{array}{l}19 \\
\text { Tahun }\end{array}$ & SMK \\
\hline 4 & $\begin{array}{l}\text { Eriyawati } \\
\text { Supardjo, } \\
\text { A.Md }\end{array}$ & $\begin{array}{l}\text { Ahli } \\
\text { Programmer }\end{array}$ & 95 & Sangat Baik & $\begin{array}{l}20 \\
\text { Tahun }\end{array}$ & DIII \\
\hline 5 & Suryani & $\begin{array}{l}\text { Ahli dibidang } \\
\text { perkantoran }\end{array}$ & 90 & Sangat Baik & $\begin{array}{l}18 \\
\text { Tahun }\end{array}$ & SMK \\
\hline
\end{tabular}

\section{Keterangan :}

Tabel 6. Nilai Asumsi Bobot Profile matching

$$
\begin{array}{|l|l|l|}
\hline \text { No } & \text { Keterangan Bobot } & \text { Nilai Bobot } \\
\hline
\end{array}
$$




\begin{tabular}{|l|l|l|}
\hline 1 & Sangat Baik & 5 \\
\hline 2 & Baik & 4 \\
\hline 3 & Cukup Baik & 3 \\
\hline 4 & Tidak Baik & 2 \\
\hline 5 & Sangat Tidak Baik & 1 \\
\hline
\end{tabular}

\section{Proses Pemetaan Gap}

Proses pemetaan yang terjadi sebenarnya memiliki satu rumus umum yang berlaku untuk menghitung bobot dari masing-masing kriteria, yaitu :

Gap = Profil Ideal - Profil Individu

Gap adalah selisih antara profil Ideal dengan profil individu untuk Calon Pegawai. Profil selajutnya dilakukan perhitungan nilai gap antara bobot profil masing-masing calon seleksi pegawai honorer dengan profile ideal, sehingga didapatkan nilai gap. Di bawah ini akan ditujukkan hasil proses pemetaan gap pada tiap kriteria.

Tabel 7. Data Nilai Profil

\begin{tabular}{|l|l|l|l|l|l|}
\hline Nama Kriteria & C1 & C2 & C3 & C4 & C5 \\
\hline A1 & 3 & 4 & 5 & 5 & 5 \\
\hline A2 & 2 & 3 & 5 & 5 & 5 \\
\hline A3 & 2 & 3 & 4 & 4 & 4 \\
\hline A4 & 2 & 3 & 4 & 3 & 5 \\
\hline A5 & 2 & 3 & 4 & 4 & 3 \\
\hline
\end{tabular}

Tabe 8. Data Nilai GAP

\begin{tabular}{|l|l|l|l|l|l|}
\hline Profil Kriteria & 4 & 4 & 3 & 2 & 2 \\
\hline Nama Kriteria & GAP C1 & GAP C2 & GAP C3 & GAP C4 & GAP C5 \\
\hline A1 & -1 & 0 & 2 & 3 & 3 \\
\hline A2 & -2 & -1 & 2 & 3 & 3 \\
\hline A3 & -2 & -1 & 1 & 2 & 2 \\
\hline A4 & -2 & -1 & 1 & 1 & 3 \\
\hline A5 & -2 & -1 & 1 & 2 & 1 \\
\hline
\end{tabular}

\section{Penentuan Bobot Gap}

Nilai bobot Gap diperoleh dari tabel aturan bobot nilai Gap dari masingmasing subkriteria dari kriteria. Nilai gap yang didapat dari proses sebelumnya yaitu proses perhitungan pemetaan gap. Hasil dari proses penentuan bobot gap kriteria.

Tabel 9. Keterangan Bobot Nilai GAP

\begin{tabular}{|l|l|l|l|}
\hline NO. & Selisih & Bobot Nilai & Keterangan \\
\hline 1 & 0 & 6 & Tidak ada selisih kompentensi sesuai dengan di butuhkan \\
\hline 2 & 1 & 5,5 & Kompentensi individu kelebihan 1 tingkat / level \\
\hline 3 & -1 & 5 & Kompentensi individu kekurangan 1 tingkat / level \\
\hline 4 & 2 & 4,5 & Kompentensi individu kelebihan 2 tingkat / level \\
\hline 5 & -2 & 4 & Kompentensi individu kekurangan 2 tingkat / level \\
\hline 6 & 3 & 3,5 & Kompentensi individu kelebihan 3 tingkat / level \\
\hline 7 & -3 & 3 & Kompentensi individu kekurangan 3 tingkat / level \\
\hline 8 & 4 & 2,5 & Kompentensi individu kelebihan 4 tingkat / level \\
\hline
\end{tabular}




\begin{tabular}{|l|l|l|l|}
\hline NO. & Selisih & Bobot Nilai & Keterangan \\
\hline 9 & -4 & 2 & Kompentensi individu kekurangan 4 tingkat / level \\
\hline 10 & 5 & 1,5 & Kompentensi individu kelebihan 5 tingkat / level \\
\hline 11 & -5 & 1 & Kompentensi induvidu kekurangan 5 tingkat / level \\
\hline
\end{tabular}

Tabel 10. Konversi Nilai ke Bobot

\begin{tabular}{|l|l|l|l|l|l|}
\hline Nama Kriteria & MAP GAP C1 & MAP GAP C2 & MAP GAP C3 & MAP GAP C4 & MAP GAP C5 \\
\hline A1 & 5 & 6 & 4.5 & 3.5 & 3.5 \\
\hline A2 & 4 & 5 & 4.5 & 3.5 & 3.5 \\
\hline A3 & 4 & 5 & 5.5 & 4.5 & 4.5 \\
\hline A4 & 4 & 5 & 5.5 & 5.5 & 3.5 \\
\hline A5 & 4 & 5 & 5.5 & 4.5 & 5.5 \\
\hline
\end{tabular}

4. Perhitungan dan Pengelompokan Core Factory dan Secondary Factor

Setelah proses penentuan bobot gap dari setiap kriteria, kemudian kriteria dikelompokkan lagi menjadi dua kelompok yaitu core factor dan secondary factor.

$\mathrm{NSF}=\frac{\Sigma N S}{\Sigma I S}$

\section{Nilai secondary Factor}

Alternatif $1: \mathrm{NSF} 1=(3,5+3,5) / 2=3,5$

Alternatif $2: \mathrm{NSF} 1=(3,5+3,5) / 2=3,5$

Alternatif $3: \mathrm{NSF} 1=(4,5+4,5) / 2=4,5$

Alternatif $4: \mathrm{NSF} 1=(5,5+3,5) / 2=4,5$

Alternatif $5: \mathrm{NSF} 1=(4,5+5,5) / 2=5,0$

Tabel 11. Secondary Factor

\begin{tabular}{|l|l|l|}
\hline NO & Nama Alternatif & Secondary Factor \\
\hline 1 & A1 & 3,5 \\
\hline 2 & A2 & 3,5 \\
\hline 3 & A3 & 4,5 \\
\hline 4 & A4 & 4,5 \\
\hline 5 & A5 & 5,0 \\
\hline
\end{tabular}

Perhitungan core factor dapat dilihat pada persamaan (2) :

$\mathrm{NCF}=\frac{\Sigma N C}{\Sigma I C}$

1. $\mathrm{NCF} 1=\frac{5+6+4,5}{3}=5,2$

2. $\mathrm{NCF} 2=\frac{4+5+4,5}{3}=4,5$

3. $\mathrm{NCF} 3=\frac{4+5+5,5}{3}=4,8$

4. $\mathrm{NCF} 4=\frac{4+5+5,5}{3}=4,8$

5. $\mathrm{NCF} 5=\frac{4+5+5,5}{3}=4,8$

Tabel 12. Core Factor 


\begin{tabular}{|l|l|}
\hline Nama Alternatif & Hasil NCF \\
\hline A1 & 5,2 \\
\hline A2 & 4,5 \\
\hline A3 & 4,8 \\
\hline A4 & 4,8 \\
\hline A5 & 4,8 \\
\hline
\end{tabular}

Keterangan :

$\mathrm{NCF}=$ Nilai rata-rata core factor

$\mathrm{NC}=$ Jumlah total core factor

IC = Jumlah subkriteria core factor

Dan untuk perhitungan secondary factor dapat dilihat pada persamaan (3) :

Nilai dokumen core factor dan secondary factor diperoleh dengan mencari nilai rata-rata dari subkriteria berdasarkan pengelompokan. Hasil proses perhitungan core factor dan secondary factor.

\section{Perhitungan Nilai Total}

Dari hasil perhitungan NCF dan NSF tiap kriteria, kemudian dihitung nilai total berdasarkan presentase dari bobot core factor dan secondary factor yang diperkirakan berpengaruh terhadap tiap-tiap nilai target calon Pegawai Honorer. Perhitungan nilai total dilakukan dengan menggunakan persamaan (4) dan (5) seperti dibawah ini:

$$
\text { Nilai Total (Ada SubKreteria) }=60 \% \mathrm{NCF}+40 \% \mathrm{NSF}
$$

Tabel 13. Konversi Nilai Total

\begin{tabular}{|l|l|l|l|l|}
\hline No & Nama & CF & SF & Total Nilai \\
\hline 1 & A1 & 5.2 & 3.5 & 4.52 \\
\hline 2 & A2 & 4.5 & 3.5 & 4.10 \\
\hline 3 & A3 & 4.8 & 4.5 & 4.68 \\
\hline 4 & A 4 & 4.8 & 4.5 & 4.68 \\
\hline 5 & A5 & 4.8 & 5 & 4.88 \\
\hline
\end{tabular}

Nilai Total (Tidak Ada SubKriteria) = Bobot Nilai Gap

Hasil proses perhitungan nilai total kriteria

\section{Perhitungan Hasil Akhir}

Nilai dari perhitungan hasil akhir akan dijadikan sebagai penentuan dalam proses perankingan.

Tabel 14. Hasil Akhir

\begin{tabular}{|l|l|l|}
\hline No & Nama & Hasil Akhir \\
\hline 1 & A1 & 4.52 \\
\hline 2 & A2 & 4.10 \\
\hline 3 & A3 & 4.68 \\
\hline
\end{tabular}

Seleksi Calon Pegawai Honorer (Silvia Ayu) | 908 


\begin{tabular}{|l|l|l|}
4 & A4 & 4.68 \\
\hline 5 & A5 & 4.88 \\
\hline
\end{tabular}

\section{Proses Perankingan}

Ini adalah tahap akhir dari proses perhitungan dengan metode Profile Matching. Dengan menggunakan nilai dari hasil akhir, kemudian diurutkan mulai dari calon Pegawai Honorer yang memiliki hasil akhir paling tinggi.

Tabel 15. Hasil Akhir Proses Perangking

\begin{tabular}{|l|l|l|l|l|}
\hline No & Nama & Nama Pegawai & Hasil Akhir & Rank \\
\hline 1 & A5 & Suryani & 4.88 & 1 \\
\hline 2 & A3 & Rangga Muhammad Nugraha & 4.68 & 2 \\
\hline 3 & A4 & Eriyawati Supardjo, A.Md & 4.68 & 3 \\
\hline 4 & A1 & Sugeng Adi Prasetyo, S.T & 4.52 & 4 \\
\hline 5 & A2 & Rika Andriani & 4.10 & 5 \\
\hline
\end{tabular}

\section{KESIMPULAN}

Dari penelitian yang telah dilakukan maka kesimpulan yang dapat diambil dalam seleksi calon pegawai honorer adalah sebagai berikut:

a. Pada penelitian ini telah menampilkan hasil berupa calon pegawai honorer yang lulus seleksi menjadi pegawai honorer dengan menampilkan data berupa perankingan sesuai dengan alternatif dan kriteria yang telah disediakan. Alternatif yang terpilih menjadi ranking pertama dan layak menjadi pegawai honorer yaitu alternatif 5 dengan hasil akhir 4,88 atau 4,9 pada sistem.

b. Metode profile matching manjadi alat dalam membantu pemilihan serta perhitungan penelitian yang dilakukan. Dalam metode ini telah dilakukan pencocokan sehingga mendapatkan hasil yang diinginkan.

c. Dalam perhitungan manual, hasil yang didapatkan akurat karena dapat dibuktikan dengan sistem serta menampilkan hasil perankingan yang sama baik nilai selisih, CF dan NF serta nilai ranking dari masing-masing alternatif

\section{DAFTAR PUSTAKA}

[1] E. Faizal, "Implementasi Metode Profile matching untuk Penentuan Penerimaan Usulan Penelitian Internal Dosen STMIK El Rahma," no. January 2014, 2017.

[2] M. M. Amin and E. Cofriyanti, "Sistem rekomendasi pemilihan kandidat calon tenaga kerja menggunakan model," pp. 108-115, 2017.

[3] I. Parlina, A. P. Windarto, A. Wanto, and M. R. Lubis, "Memanfaatkan Algoritma K-Means Dalam Menentukan Pegawai yang Layak Mengikuti Asessment Center," CESS Uournal Comput. Eng. Syst. Sci., vol. 3, no. 1, pp. 87-93, 2018.

[4] A. P. Windarto, "Implementation of Data Mining on Rice Imports by Major Country of Origin Using Algorithm Using K-Means Clustering Method," Int. J. Artif. Intell. Res., vol. 1, no. 2, pp. 26-33, 2017.

[5] Sudirman, A. P. Windarto, and A. Wanto, "Data mining tools | rapidminer : K-means method on clustering of rice crops by province as efforts to stabilize food crops in Indonesia," in IOP Conference Series, 2018, pp. 1-8. 